Helena GASPARS-WIELOCH, Ph.D.

Faculty of Informatics and Electronic Economy, Poznań University of Economics and Business e-mail: helena.gaspars@ue.poznan.pl

\title{
A DECISION RULE FOR UNCERTAIN MULTI-CRITERIA PURE DECISION MAKING AND INDEPENDENT CRITERIA ${ }^{1}$
}

\begin{abstract}
Summary
The paper is concerned with multi-criteria decision-making under uncertainty with scenario planning. This topic has been explored by many researchers since almost all real-world decision problems contain multiple conflicting criteria and a deterministic evaluation of criteria is often impossible. We propose a procedure for uncertain multi-objective optimization which can be applied when seeking a pure strategy. A pure strategy, as opposed to a mixed strategy, allows the decision-maker to select and perform only one accessible alternative. The new approach takes into account the decision-maker's preference structure (importance of particular goals) and nature (pessimistic, moderate or optimistic attitude towards a given problem). It is designed for one-shot decisions made under uncertainty with unknown probabilities (frequencies), see decision-making under complete uncertainty or decision-making under strategic uncertainty. The novel approach can be used in the case of totally independent payoff matrices for particular targets.
\end{abstract}

Keywords: uncertainty, multi-criteria decision-making, pure strategies, one-shot decisions, independent criteria, two-stage models.

JEL: C44, D81, L21.

\section{Introduction}

Multiple criteria decision-making with uncertain attribute (criterion) evaluations has been theoretically and practically investigated by many researchers since usually real decision problems contain numerous conflicting criteria and a deterministic evaluation of criteria is often impossible. [Durbach and Stewart 2012] prepared an impressive review of possible models, methods and tools supporting uncertain multi-criteria decisionmaking (e.g. models with explicit risk measures, models with scenarios, models with fuzzy numbers, models using probabilities or probability-like quantities) [GasparsWieloch, 2015c]. In this paper we propose a method designed for multi-criteria decision- making with scenario planning and one-shot decision problems (we assume that

${ }^{1}$ This research is financed by the National Science Center in Poland (project registration number: 2014/15/D/HS4/00771). 
after the realization of a selected alternative the decision-maker may change his/her preferences - thus, multi-shot decisions are not considered). We analyze the case of games against nature (not games with other players). We assume that criteria payoff matrices are independent and that, within each criterion, payoffs connected with a given decision constitute sequences of outcomes (not sets of outcomes). We will refer to a multi-criteria two-stage model. The target of the new approach is to select an optimal pure strategy, which means that only one alternative is selected and performed. The procedure takes into consideration decision-makers' objective preferences and their attitude towards the risk connected with a given problem. This attitude is measured by the coefficient of optimism on the basis of which a set of events having the biggest subjective chance of occurrence (separately for each payoff matrix) is suggested. Such an approach allows us to reduce the quantity of data considered in the final decision selection.

The paper is organized as follows. Section 2 deals with the main features of MDMU (multi-criteria decision-making under uncertainty), scenario planning, 1-stage and 2-stage models. Section 3 presents a procedure that can be used as a tool in multi-criteria optimization under uncertainty for pure strategies and independent payoff matrices. Section 4 provides a case study on the basis of the bi-criteria single-period newsvendor problem. Conclusions are gathered in the last Section. The paper is a continuation of several articles, where uncertain one-criterion procedures [Gaspars-Wieloch, 2007; 2014a; 2014c; 2015b; 2016b] and multi-criteria decision rules [Gaspars-Wieloch, 2014d; 2015c; 2015d; 2017] are investigated.

\section{How to combine criteria with scenarios in uncertain multi-criteria decision making when criteria are independent?}

The necessity to solve decision problems with uncertain parameters led to the development of many diverse theories [Zio, Pedroni, 2013], e.g. probability theory [Kolmogorov, 1933], possibility theory [Zadeh, 1978; Dubois, Prade, 2001], imprecise (interval) probability [Walley, 1991], uncertainty theory [Liu, 2007; 2009], credibility theory, evidence theory [Shafer, 1976; Sentz, Ferson, 2002]. Nevertheless, it is worth emphasizing that there is no unanimity in defining the notion of uncertainty and that there are many types of uncertainty. The three next paragraphs are prepared on the basis of [Gaspars-Wieloch, 2016a; 2017].

According to the theory of decision the decision-maker (DM) may choose the appropriate alternative (decision, strategy, variant) under certainty (DMC - parameters are deterministic), under risk (DMR - possible scenarios and their likelihood are known), with partial information (DMPI - possible states of nature are known, but their probability is not completely known), under complete uncertainty (DMCU - scenarios are known, but not the probability of their occurrence) or under total ignorance (DMTI - the DM is not able to define possible events). Note that DMCU may also occur when the DM does not want to make use of the estimated probability distribution [Trzaskalik, 2008]. Comments concerning particular decision-making circumstances can be found for instance in [Guo, 2011; Kaplan, Barish, 1967; Knight, 1921; Perez et al., 2015; Render et al., 2006; 
Sikora, 2008; Waters, 2011; Weber, 1987]. Uncertainty and risk were formally integrated in economic theory by [von Neuman and Morgenstern 1944].

Supporters of the theory of economics state that uncertainty involves all situations with non-deterministic parameters (known, unknown or incompletely known probability distribution, lack of information about possible scenarios), while risk is related to the possibility that some bad (or other than predicted) circumstances will happen [Dominiak, 2009; Dubois, Prade, 2012; Fishburn, 1984; Gaspars-Wieloch, 2016a; Guney, Newell, 2015; Ogryczak, Sliwinski, 2009; Waters, 2011]. Note that in some cases the exact probability computation may be difficult due to: 1 ) the existence of diverse definitions of probability [Carnap, 1950; De Finetti, 1975; Frechet, 1938; Hau et al., 2009; Knight, 1921; Kolmogorov, 1933; Piegat, 2010; Popper, 1959; Ramsey, 1931; Van Lambalgen, 1996; Von Mises, 1949; Von Mises, 1957], 2) the lack of historical data (for totally new decisions and events) [Gaspars-Wieloch, 2016a; Guo, 2011; Guo, Ma, 2014], 3) the lack of sufficient knowledge about particular states or 4) the fact that the set of possible scenarios forecasted by experts in the scenario planning stage does not satisfy probability axioms (the sum of state probabilities should be equal to 1 , the whole sample space must be precisely defined), see [Kolmogorov, 1933]. Caplan [2001] states that sometimes people may be even unable to declare subjective probabilities, but they implicitly set the likelihood in acting. Nevertheless, within the theory of economics, even if the probability is not known, some probability-like quantities can often be estimated and applied. Hence, uncertainty, in many cases, can be measured and quantified somehow [Piasecki, 2016].

Besides two aforementioned approaches, it is worth mentioning the Austrian Economic School which treats uncertainty as do decision theorists, i.e. as a situation where the likelihood is not known. Additionally, it is assumed that the mathematical probability of the occurrence of a given scenario is not known as probabilities only concern repetitive events, meanwhile in the majority of real problems the DM deals with non-repetitive events. According to [Von Mises, 1949], the theory of probability can never lead to a definite statement concerning a single event (the probability of a single event cannot be presented numerically). Uncertainty is not caused by the randomness of events (as held by mainstream economists) but is due to numerous factors, of which only some are known in the decision-making process [Gaspars-Wieloch, 2017].

Note that scientists distinguish two main types of uncertainty: the epistemic (reducible) uncertainty - due to the lack of knowledge (it can be reduced or eliminated after collecting information), and the aleatory (aleatoric, random) uncertainty - due to the inherent variability in a physical phenomenon (it cannot be reduced even after conducting $n$ experiments) [Stirtling, 2003; Zio, Pedroni, 2013].

In this paper we consider both epistemic and aleatory uncertainty, which leads us to a conclusion that the likelihood of the occurrence of particular states of nature cannot be estimated in an accurate way (the aleatory uncertainty is not reducible). Additionally, in connection with the fact that the contribution concerns only one-shot decisions, we refer in a sense to the Austrian approach where the probability understood as frequency cannot be computed for a single event. The theory of economics is also partially applied 
in this research since unknown probabilities are replaced with some secondary probabilitylike quantities.

It is worth adding that, as a matter of fact, scientists declare different opinions concerning the role of probability in scenario planning (SP). Some of them state that the likelihood should not be applied to SP [Michnik, 2013]. Others are convinced that there are many advantages of using probabilities in SP [Millett, 2009].

The notion "uncertainty" has been just briefly discussed. Now, let us analyze possible ways of inserting uncertainty in multi-criteria decision-making. Many classical and extended decision rules designed for pure or mixed MDMU (multi-criteria decision-making under uncertainty) have been already developed, e.g. [Aghdaie et al., 2013; Ben Amor et al., 2007; Dominiak, 2006; 2009; Durbach, 2014; Eiselt, Marianov, 2014; GasparsWieloch, 2014d; 2015c; 2015d; 2017; Ginevičius, Zubrecovas, 2009; Goodwin, Wright, 2001; Hopfe et al., 2013; Janjic et al., 2013; Korhonen, 2001; Lee, 2012; Liu et al., 2011; Lo, Michnik, 2010; Michnik, 2013; Mikhaidov, Tsvetinov, 2004; Montibeller et al., 2006; Ram et al., 2010; Ramik et al., 2008; Ravindran, 2008; Silva, 2016; Stewart, 2005; Suo et al., 2012; Troutt, Pettypool, 1989; Tsaur et al., 2002; Urli, Nadeau, 2004; Wojewnik, Szapiro, 2010; Xu, 2000; Yu, 2002]. Some of them can be applied when the DM intends to perform the selected alternative only once (one-shot decisions). Others are recommended for people considering multiple realizations of the chosen variant (multi-shot decisions). In the aforementioned contributions diverse tools connected with uncertainty are used, e.g. probabilities, belief functions, fuzzy membership functions. However [Durbarch, Stewart, 2012] underline that uncertainties become increasingly so complex that the elicitation of such measures becomes operationally difficult for DMs to comprehend and virtually impossible to validate. Therefore, in their opinion, it is useful to construct scenarios which describe possible ways in which the future might unfold and to combine MDMU with SP (scenario planning). And then, the result of the choice made under uncertainty with scenario planning depends on two factors: which decision will be chosen and which state of nature will occur [Gaspars-Wieloch, 2015c].

According to [Durbarch, Stewart, 2012; Michnik, 2013] MDMU+SP models can be divided into two classes (the description below has been prepared on the basis of [Gaspars-Wieloch, 2014d; 2015c; 2015d; 2017]). The first one (A) includes 2-stage models in which evaluations of particular alternatives are estimated in respect of scenarios and criteria in two separate stages. Class A contains two subclasses: A-CS and A-SC. Subclass A-CS denotes the set of approaches considering decisions separately in each scenario and setting a $n \times m$ table ( $n$ - number of decisions, $m$ - number of scenarios) giving the aggregated (over attributes/criteria) performance of alternative $D_{j}$ under scenario $S_{i .}$. These evaluations are then aggregated over scenarios. In subclass A-SC the order of aggregation is reversed - performances are generated across scenarios and measures are then calculated over criteria. The second class (B) consists of one-stage procedures considering all combinations of scenarios and attributes (scenario-criterion pairs) as distinct meta-criteria and using a chosen multiple criteria approach for the transformed meta-matrix. There is currently no consensus on the best way to solve uncertain multigoal problems [Durbarch and Stewart 2012]. Let us emphasize that subclass A-CS 
may be only applied to dependent payoff matrices. Hence, the number of events ought to be the same for each criterion considered in the decision problem and evaluation $a_{i j}^{k}$ can only be connected with evaluations $a_{i j}{ }^{1}, \ldots, a_{i j}^{k-1}, a_{i j}^{k+1}, \ldots, a_{i j} j^{-1}$ and $a_{i j}$ (those values describe the performance of each criterion by decision $D_{j}$ provided that scenario $S_{i}$ happens) where $p$ is the number of criteria. On the other hand, subclass A-SC should merely be used for independent payoff matrices, which means that this time there is no relationship between criteria. The performance of particular targets can be analyzed totally separately since the number of states of nature can be different for each goal $\left(m_{1}, m_{2}, \ldots, m_{k}, \ldots, m_{p}\right)$. In the second case, evaluation $a_{i j}{ }^{k}$ might be connected with any evaluation $a_{i j}{ }^{1}\left(i=1, \ldots, m_{1}\right)$, any evaluation $a_{i j}^{2}\left(i=1, \ldots, m_{2}\right), \ldots$ and any evaluation $a_{i} f\left(i=1, \ldots, m_{p}\right)$. Those values describe the performance of each criterion by decision $D_{j}$ assuming that any scenario occurs for criteria $C_{1}, \ldots, C_{k-1}, C_{k+1}, \ldots, C_{p}$. One-stage models (i.e. class B) are also designed for independent payoff matrices.

Subclass A-SC from two-stage models, combined simultaneously with uncertain multi-criteria pure decision-making, games against nature, probability-like quantities, scenario forecasting stage and independent criteria, hasn't so far been analyzed in the literature. Nevertheless, we would like to investigate this topic, since it gives us the possibility to elaborate a procedure focusing on events having the biggest subjective chance of occurrence. Note that the set of aforementioned scenarios will not be directly predicted by the DM - it will be indirectly generated on the basis of his/her coefficient of optimism.

\section{Procedure for MDMU+SP, pure strategies and independent criteria}

The discrete version (i.e. the set of alternatives is explicitly defined and discrete) of MDMU+SP with independent payoff matrices consists of $n$ decisions $\left(D_{1}, \ldots, D_{j}\right.$, $\left.\ldots, D_{n}\right)$, each evaluated on $p$ criteria $\left(C_{1}, \ldots, C_{k}, \ldots, C_{p}\right)$ and $m_{k}$ mutually exclusive scenarios $\left(S^{k_{1}}, \ldots, S^{k}, \ldots, S^{k}{ }_{m k}\right)$ where $k=1, \ldots, p$. The problem can be presented by means of $p$ payoff matrices (one for each criterion) and $n \times\left(m_{1}+\ldots+m_{k}+\ldots+m_{p}\right)$ evaluations. Each payoff matrix contains $n \times m_{k}$ evaluations, say $a_{i j}{ }^{k}$, which denotes the performance of criterion $C_{k}$ resulting from the choice of decision $D_{j}$ and the occurrence of scenario $S^{k}{ }_{i}$. We assume that the distribution of payoffs related to a given decision is discrete.

Instead of using probabilities, we will apply here the coefficients of optimism $(\beta)$ and pessimism (a). They allow us to take into account the DM's nature (attitude towards a given problem) and to generate some secondary probability-like quantities. These parameters belong to interval $[0,1]$ and satisfy the condition $a+\beta=1$, where $a(\beta)$ tends to 0 (1) for extreme optimists (risk-prone behavior) and is close to 1 (0) for radical pessimists (risk-averse behavior). The coefficients of pessimism and optimism have been already used in decision rules suggested for instance by [Gaspars-Wieloch, 2014b; 2015a; Hurwicz, 1952; Perez et al., 2015].

The procedure presented in this Section considers DM's preferences (criteria weights) and suppositions (optimism/pessimism level, indirect choice of the scenarios with the biggest subjective chance of occurrence). 
The suggested method (based on subclass A-SC) consists of the following steps: 1) Given a set of potential decisions and payoff matrices for each criterion, define an appropriate value of parameter $\beta \in[0,1]$ according to your level of optimism, and choose weights $w^{k}$ for each attribute $(k=1, \ldots, p)$. The weights ought to describe the importance of each target and should satisfy Equation (1):

$$
\sum_{k=1}^{p} w^{k}=1
$$

2) If necessary (i.e. when criteria are presented in different scales or units), normalize the evaluations (use Equation (2) for maximized criteria and Equation (3) for minimized criteria) separately within each payoff matrix:

$$
\begin{gathered}
a(n)_{i j}^{k}=\frac{a_{i j}^{k}-\min _{\substack{i=1, \ldots, m \\
j=1, \ldots, n}}\left\{a_{i j}^{k}\right\}}{\max _{\substack{i=1, \ldots, m \\
j=1, \ldots, n}}\left\{a_{i j}^{k}\right\}-\min _{\substack{i=1, \ldots, m \\
j=1, \ldots, n}}\left\{a_{i j}^{k}\right\}} \quad i=1, \ldots, m_{k} ; j=1, \ldots, n ; k=1, \ldots, p \\
a(n)_{i j}^{k}=\frac{\max _{\substack{i=1, \ldots, m \\
j=1, \ldots, n}}\left\{a_{i j}^{k}\right\}-a_{i j}^{k}}{\max _{\substack{i=1, \ldots, m \\
j=1, \ldots, n}}\left\{a_{i j}^{k}\right\}-\min _{\substack{i=1, \ldots, m \\
j=1, \ldots, n}}\left\{a_{i j}^{k}\right\}} \quad i=1, \ldots, m_{k} ; j=1, \ldots, n ; k=1, \ldots, p
\end{gathered}
$$

where $a(n)^{k_{i j}}$ denotes the normalized evaluation of $a^{k_{i j}}$. Expressions $\max \left\{a^{k_{i j}}\right\}$ and $\min \left\{a^{k}{ }_{i j}\right\}$ signify the highest and the lowest evaluation of criterion $C_{k}$ in payoff matrix related to this attribute.

3) Compute the sum of cumulative relative profits $\left(p(r)^{k_{i}}\right)$ for each scenario (separately for each criterion).

$$
\begin{array}{rc}
p(r)_{i}^{k}=\sum_{j=1}^{n} p(r)_{i j}^{k} & i=1, \ldots, m_{k} ; k=1, \ldots, p \\
p(r)_{i j}^{k}=m_{k} \cdot a(n)_{i j}^{k}-\sum_{i=1}^{m_{k}} a(n)_{i j}^{k} & i=1, \ldots, m_{k} ; j=1, \ldots, n ; k=1, \ldots, p
\end{array}
$$

This step allows identifying scenarios that are relatively better than others. In the contribution, the dominance is measured by means of the distance between particular evaluations related to a given scenario and all corresponding values connected consecutive decisions. The method presented above is just a suggestion. The status of each event may be estimated in a different way.

4) Choose the set of scenarios with the biggest chance of occurrence for each criterion separately:

a) If there exists at least one scenario for which the sum of relative profits is exactly equal to the value given by Equation (6), the set of events with the biggest chance of occurrence $\left(S S^{k^{*}}\right)$ contains all such states of nature (the number of scenarios belonging to that set is denoted by $m_{k^{*}}$ ). Go to step $5 \mathrm{a}$. 


$$
\begin{array}{cc}
p(r)_{\beta}^{k}=\beta \cdot\left(p(r)_{\max }^{k}-p(r)_{\min }^{k}\right)+p(r)_{\min }^{k} & k=1, \ldots, p \\
p(r)_{\max }^{k}=\max _{i}\left\{p(r)_{i}^{k}\right\} & k=1, \ldots, p \\
p(r)_{\min }^{k}=\min _{i}\left\{p(r)_{i}^{k}\right\} & k=1, \ldots, p
\end{array}
$$

b) If there is no scenario fulfilling Equation (6), find all events $S k, \beta_{\min }$ satisfying condition (9) - the set containing such states of nature is denoted by $S S k^{*}$ min

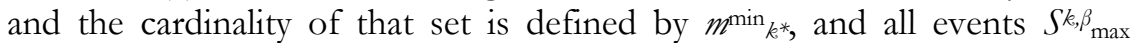
satisfying condition (10) - the set containing such scenarios is denoted by

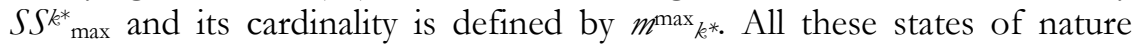
constitute the set of scenarios with the biggest chance of occurrence (i.e. $\left.\int S k^{*}\right): \int S k^{*}{ }_{\min } \cup \int S k^{*}{ }_{\max }=\int S k^{*}$. Go to step $5 \mathrm{~b}$.

$$
\begin{array}{cc}
S_{\min }^{k, \beta}=\arg \min _{S_{i}^{k} \mid p(r)_{i}^{k}<p(r)_{\beta}^{k}}\left(p(r)_{\beta}^{k}-p(r)_{i}^{k}\right) & k=1, \ldots p \\
S_{\max }^{k, \beta}=\arg \min _{S_{i}^{k} \mid p(r)_{i}^{k}>p(r)_{\beta}^{k}}\left(p(r)_{i}^{k}-p(r)_{\beta}^{k}\right) & k=1, \ldots p
\end{array}
$$

Hence, we see that the choice of scenarios with the biggest change of occurrence strictly depends on the level of $\beta$. We assume that the higher the value of $\beta$, the better scenarios (i.e. with higher sums of cumulative relative profits) should be treated as events reflecting the DM's nature. Step 4b involves situations where there is no event exactly fitting the level of the coefficient of optimism (according to Equation (6)). In such circumstances, one can for instance find scenarios for which the sum of cumulative relative profits is very close to the value indicated by Equation (6).

5) a) Calculate average values for each decision according to Equation (11), separately for each criterion.

$$
v_{j}^{k}=\frac{1}{m_{k^{*}}} \cdot \sum_{S_{i}^{k} \in S S^{k^{*}}} a(n)_{i j}^{k} \quad j=1, \ldots . n ; k=1, \ldots, p
$$

b) Calculate weighted values for each decision according to Equation (12), separately for each criterion.

$$
\begin{array}{r}
v_{j}^{k}=\frac{1}{m_{k^{*}}^{\max }} \cdot \sum_{S_{i}^{k} \in S S_{\max }^{k^{*}}} a(n)_{i j}^{k} \cdot \frac{p(r)_{\beta}^{k}-p(r)_{\min }^{k^{*}}}{p(r)_{\max }^{k^{*}}-p(r)_{\min }^{k^{*}}}+\frac{1}{m_{k^{*}}^{\min }} \cdot \sum_{S_{i}^{k} \in S S_{\min }^{k^{*}}} a(n)_{i j}^{k} \cdot \frac{p(r)_{\max }^{k^{*}}-p(r)_{\beta}^{k}}{p(r)_{\max }^{k^{*}}-p(r)_{\min }^{k^{*}}} \\
j=1, \ldots . . n ; k=1, \ldots, p
\end{array}
$$

In this step all evaluations connected with a given alternative and related to set $S S k^{*}$ are aggregated in order to generate only one index for each decision within each criterion. In step $5 \mathrm{a}$ the weight of each value is the same since all of them come from scenarios with the same level of the sum of cumulative relative profits. On the other hand, in step $5 b$ weights for particular values may be different as the differences between sums of cumulative relative profits and the theoretical one (defined by Equation (6)) may 
be diverse, depending on the scenario. The aggregation performed in step 5 completes the first stage of the 2 -stage model.

6) Compute a weighted index for each decision across all criteria, using the SAW method (Simple Additive Weighting Method).

$$
S A W_{j}=w^{k} \cdot v_{j}^{k} \quad j=1, \ldots . n
$$

7) Choose the final pure strategy:

a) Find the alternative fulfilling Equation (14).

$$
D_{j^{*}}=\arg \max _{j}\left(S A W_{j}\right)
$$

b) If $D_{j *}$ satisfies condition (15) for the criterion with the highest weight $w^{k}, D_{j *}$ is the optimal pure strategy.

$$
\begin{array}{cc}
\underset{t \in\left\{1,2, \ldots, z_{k}\right\}}{\forall}\left(a(n)_{t, j^{*}} \geq \text { wald }_{\text {best }}^{k}\right) & k \mid w^{k}=\max _{k}\left\{w^{k}\right\} \\
z_{k}=\left\lceil(1-\beta) \cdot m_{k}\right\rceil=\left\lceil\alpha \cdot m_{k}\right\rceil & k \mid w^{k}=\max _{k}\left\{w^{k}\right\} \\
a(n)_{1, j^{*}} \geq \ldots \geq a(n)_{t, j^{*}} \geq \ldots \geq a_{z_{k}, j^{*}} & j=1, \ldots, n ; k \mid w^{k}=\max _{k}\left\{w^{k}\right\} \\
\text { wald }_{j}^{k}=\min _{i}\left\{a(n)_{i j}^{k}\right\} & k \mid w^{k}=\max _{k}\left\{w^{k}\right\}
\end{array}
$$

where $2 k$ is the minimal number of scenarios for which normalized outcomes should be at least equal to wald ${ }^{k}$ best. The last symbol denotes the highest value of Wald index for the criterion with the highest weight $w^{k}$.

c) If $D_{j *}$ does not fulfill condition (15), find $D_{j * *}$ satisfying Equation (20). Note that such a decision always exists.

$$
\left(S A W_{j} \rightarrow \max \right) \wedge\left(\underset{t \in\left\{1,2, \ldots, z_{k}\right\}}{\forall}\left(a(n)_{t, j} \geq \text { wald }_{\text {best }}^{k}\right)\right) \quad k \mid w^{k}=\max _{k}\left\{w^{k}\right\}
$$

Step 7 also requires additional explanations. As a matter of fact, we could have stopped the algorithm after step 7a. Nevertheless, the choice of the final alternative merely on the basis of Equation (14) may be unfair especially for moderate and radical pessimists who feel more safely when the procedure provides necessary securities. For a radical pessimist, Equations (15)-(20) guarantee that even if the worst scenario connected with the selected decision and the most important criterion occurs, the outcome related to this goal will not be lower than the Wald index computed for the aforementioned target. Similar securities, but to a lesser extent, are also guaranteed for other types of DMs (moderate pessimists, moderate optimists etc.). 
Let us name the procedure presented above $\beta-\mathrm{MPDM} / 2$, i.e. a method referring to parameter $\beta$, designed for multi-criteria pure decision-making and based on two-stage models. The choice of the set of events having the biggest subjective chance of occurrence (step 4) results from the fact that in the case of one-shot decisions only one scenario (within each criterion) will finally occur in the future. The use of the SAW method in step 6 is just a suggestion. Other multi-criteria approaches are also possible [Trzaskalik, 2014; Wachowicz, 2015].

\section{Case study}

The novel approach will be illustrated by means of an example concerning the bicriteria single period newsvendor problem. The one-criterion problem is described, e.g. in [Gaspars-Wieloch, 2016a; Sikora, 2008]. The newsvendor problem (NP) has attracted a great deal of attention and played a central role at the conceptual foundations of stochastic inventory theory [Bieniek, 2016]. It was originally related to decision making under stochastic uncertainty where the demand is presented as a random variable with a known probability distribution. Nevertheless, NP has also been recently discussed in the context of decision making with partial information [Guo, 2011; Guo, Ma, 2014], where the DM is able to subjectively define possibility degrees and satisfaction levels (the probability distribution is not known completely). Additionally, according to [Besbes, Muharremoglu, 2013; Benzion et al., 2010; Gaspars-Wieloch, 2016a], the newsvendor theory should not assume that the DM faces a known distribution (known frequencies), since in real-life situations the demand distribution is not always known (e.g. for innovative products where there are no data available for forecasting the upcoming demand via statistical analysis).

Les us assume that the newsvendor intends to sell a totally new short-cycle product. He assumes that the quantity procured will be solely used to satisfy the demand during the current period. The demand for this product is not known in advance. He considers order $(q)$ and demand $(D)$ quantities between 1 and 5 boxes. Hence, there are 5 alternatives: $A_{1}$ (1 box), $A_{2}$ (2 boxes), $A_{3}$ ( 3 boxes), $A_{4}$ ( 4 boxes) and $A_{5}$ ( 5 boxes). The unit production/ purchase cost of 1 box $\left(c_{1}\right)$ equals 5 , the selling price $\left(c_{2}\right)$ equals 10 and the discount price (price of leftover items) $c_{3}=1$, hence the unit profit from selling the product at price $c_{2}: b=c_{2}-c_{1}=5$ and the unit loss from selling it at price $c_{3}: s=c_{1}-c_{3}=4$. The newsvendor maximizes the total profit (e.g. in thousands of Euros) resulting from buying and selling the new product (the $1^{\text {st }}$ criterion depends on the demand - five possible scenarios) and minimizes the cost of supply (also in thousands of Euros, the $2^{\text {nd }}$ criterion depends on the supplying, storage, weather conditions - three possible scenarios). Note that the total profit does not include the cost of supply and that is equal to $b \times q$ (for $q \leq D$ ) or $b \times D-s \times(q-D)$ when $q>D$. Payoff matrices are given in Tables 1-2 (first value in each cell). The newsvendor intends to find an optimal pure strategy. Now, let us apply the procedure $\beta-\mathrm{MPDM} / 2$ for the aforementioned problem. 
TABLE 1.

Payoff matrix and normalized values (1st criterion)

\begin{tabular}{|l|c|c|c|c|c|}
\hline Crit. 1 & $\boldsymbol{A}_{\mathbf{1}}=\mathbf{1}$ & $\boldsymbol{A}_{\mathbf{2}}=\mathbf{2}$ & $\boldsymbol{A}_{\mathbf{3}}=\mathbf{3}$ & $\boldsymbol{A}_{\mathbf{4}}=\mathbf{4}$ & $\boldsymbol{A}_{\mathbf{5}}=\mathbf{5}$ \\
\hline $\boldsymbol{S}^{1}{ }_{1}=1$ & $5 / 0.44$ & $1 / 0.33$ & $-3 / 0.22$ & $-7 / 0.11$ & $-11 / 0.00$ \\
\hline$S^{1}{ }_{2}=2$ & $5 / 0.44$ & $10 / 0.58$ & $6 / 0.47$ & $2 / 0.36$ & $-2 / 0.25$ \\
\hline$S^{1}{ }_{3}=3$ & $5 / 0.44$ & $10 / 0.58$ & $15 / 0.72$ & $11 / 0.61$ & $7 / 0.50$ \\
\hline$S^{1}{ }_{4}=4$ & $5 / 0.44$ & $10 / 0.58$ & $15 / 0.72$ & $20 / 0.86$ & $16 / 0.75$ \\
\hline$S^{1}{ }_{5}=5$ & $5 / 0.44$ & $10 / 0.58$ & $15 / 0.72$ & $20 / 0.86$ & $25 / 1.00$ \\
\hline
\end{tabular}

Source: prepared by the author.

TABLE 2.

Payoff matrix and normalized values (2nd criterion)

\begin{tabular}{|l|c|c|c|c|c|}
\hline Crit. 2 & $\boldsymbol{A}_{\mathbf{1}}=\mathbf{1}$ & $\boldsymbol{A}_{\mathbf{2}}=\mathbf{2}$ & $\boldsymbol{A}_{\mathbf{3}}=\mathbf{3}$ & $\boldsymbol{A}_{\mathbf{4}}=\mathbf{4}$ & $\boldsymbol{A}_{\mathbf{5}}=\mathbf{5}$ \\
\hline$S^{2}{ }_{1}$ & $0.5 / 1.00$ & $0.6 / 0.96$ & $0.7 / 0.92$ & $0.8 / 0.87$ & $0.9 / 0.83$ \\
\hline$S_{2}{ }_{2}$ & $1 / 0.79$ & $1.1 / 0.75$ & $1.2 / 0.71$ & $1.3 / 0.67$ & $1.4 / 0.62$ \\
\hline$S^{2}{ }_{3}$ & $2 / 0.37$ & $2.2 / 0.29$ & $2.5 / 0.17$ & $2.7 / 0.08$ & $2.9 / 0.00$ \\
\hline
\end{tabular}

Source: prepared by the author.

First (step 1), we assume that the DM is a moderate optimist $(\beta=0.7, a=0.3)$ and that $w^{1}=0.7, w^{2}=0.3$. We normalize values (step 2 ) since they are expressed in different scales, see Tables 1-2 (second value in each cell). The sums of cumulative relative profits are given in Tables 3-4 (step 3). For example, $p(r){ }_{23}=5 \cdot 0.47$ $(0.22+0.47+0.72+0.72+0.72)=-0.50$ and $p(r){ }_{1}{ }_{2}=0.00+0.25-0.5-1.00-1.25=-2.50$. Now, we are going to select scenarios with the biggest subjective chance of occurrence (step 4). Measures $p(r)^{k}$ calculated for each criterion separately show the level of the sum of cumulative relative profits corresponding to the level of the DM's optimism: $p(r)^{1}{ }_{\beta}=0.7 \times(5.00-(-7.50))+(-7.50)=1.25, p(r)^{2}{ }_{\beta}=0.7 \times(4.71-(-6.29))+(-6.29)=1.41$. In the case of the $1^{\text {st }}$ criterion, index $p(r)^{1}{ }_{3}$ (i.e. for scenario $S_{3}$ ) is exactly equal to $p(r)^{1} \beta$. Hence, $S S^{1^{*}}=\left\{S_{1}{ }_{3}\right\}$. In the case of the $2^{\text {nd }}$ criterion, there is no scenario for which index $p(r)^{2}=p(r)^{2} \beta$. Thus, according to step $4 \mathrm{~b}, S S^{2^{*}}=S S^{2^{*}{ }_{\text {min }}} \cup S S^{2^{*}}{ }_{\max }=\left\{S_{3}\right\} \cup\left\{S_{2}\right\}=\left\{S_{2}, S_{3}\right\}$. Within step 5, we compute, for each decision, average values for criterion $C_{1}$ (Equation 11): $v_{1}^{1}=0.44, v_{2}^{1}=0.58, v_{3}^{1}=0.72, v_{4}^{1}=0.61, v^{1}{ }_{5}=0.50$ where $m_{1 *}=1$, and weighted values for criterion $C_{2}$ (Equation 12): $v^{2}{ }_{1}=0.78, v_{2}^{2}=0.74, v_{3}=0.70, v_{4}=0.65, v_{5}=0.61$, where $m^{\max }{ }_{2^{*}}=1, m^{\min }{ }_{2^{*}}=1$ and $p(r)^{2 *}{ }_{\max }=1.58, p(r)^{2^{*}}{ }_{\min }=-6.29$. In step 6, SAW indices are calculated: $S A W_{1}=0.7 \cdot 0.44+0.3 \cdot 0.78=0.55, S A W_{2}=0.63, S A W_{3}=0.71, S A W_{4}=0.62$, $S A W_{5}=0.53$. According to Equation 14 (step 7), alternative $A_{3}$ should be selected, but first, let us check whether for the most important criterion (i.e. the first one: $w^{1}>w^{2}$ ) an appropriate number of normalized outcomes (i.e. at least $z_{1}=\lceil(1-0.7) \cdot 5\rceil=\lceil 0.3 \cdot 5\rceil=2$ ) connected with $A_{3}$ exceeds the Wald index: wald ${ }^{1}{ }_{\text {best }}=\max \{0.44,0.33,0.22,0.11$, $0.00\}=0.44$. We see in Table 1 that there are four normalized values equal to at least 0.44 , i.e. $0.47,0.72,0.72$ and 0.72 . Therefore, $A_{3}$ satisfies condition (15) and becomes the final optimal solution. The newsvendor should buy 3 boxes. This is the optimal 
pure strategy for one period. If he intends to define the best solution for further periods, he should update his preferences and possibly payoff matrices.

TABLE 3.

\section{Sums of cumulative relative profits (1st criterion)}

\begin{tabular}{|c|c|c|c|c|c|c|}
\hline Crit. 1 & $A_{1}=1$ & $A_{2}=2$ & $A_{3}=3$ & $A_{4}=4$ & $A_{5}=5$ & Sum $p(t)^{k_{i}}$ \\
\hline$S_{1}^{1}=1$ & 0.00 & -1.00 & -1.75 & -2.25 & -2.50 & -7.50 \\
\hline$S_{2}^{1}=2$ & 0.00 & 0.25 & -0.50 & -1.00 & -1.25 & -2.50 \\
\hline$S_{3}^{1}=3$ & 0.00 & 0.25 & 0.75 & 0.25 & 0.00 & 1.25 \\
\hline$S_{4}^{1}=4$ & 0.00 & 0.25 & 0.75 & 1.50 & 1.25 & 3.75 \\
\hline$S^{1}{ }_{5}=5$ & 0.00 & 0.25 & 0.75 & 1.50 & 2.50 & 5.00 \\
\hline
\end{tabular}

Source: prepared by the author.

TABLE 4.

\section{Sums of cumulative relative profits (2nd criterion)}

\begin{tabular}{|l|c|c|c|c|c|c|}
\hline Crit. 2 & $\boldsymbol{A}_{\mathbf{1}}=\mathbf{1}$ & $\boldsymbol{A}_{\mathbf{2}}=\mathbf{2}$ & $\boldsymbol{A}_{\mathbf{3}}=\mathbf{3}$ & $\boldsymbol{A}_{\mathbf{4}}=\mathbf{4}$ & $\boldsymbol{A}_{\mathbf{5}}=\mathbf{5}$ & Sum \\
\hline$S^{2}{ }_{1}=1$ & 0.83 & 0.88 & 0.96 & 1.00 & 1.04 & 4.71 \\
\hline$S^{2}{ }_{2}=2$ & 0.21 & 0.25 & 0.33 & 0.38 & 0.42 & 1.58 \\
\hline$S^{2}{ }_{3}=3$ & -1.04 & -1.13 & -1.29 & -1.38 & -1.46 & -6.29 \\
\hline
\end{tabular}

Source: prepared by the author.

\section{Conclusions}

The paper contains a description of a decision rule supporting multi-criteria decision making under uncertainty with unknown probabilities (understood as frequencies). Probabilities are not given here as initial data. Instead of it, some secondary probabilitylike quantities are used. The goal of the procedure is to find an optimal pure strategy which constitutes a one-shot decision (it is executed only once). The method is designed for games against nature. It is based on two-stage models. Advantages of applying that approach are as follows: 1) It does not require any information about probabilities, which is especially desirable in the case of new decision problems, 2) It takes into consideration the decision-maker's preference structure and nature, but only criteria weights and the level of optimism are supposed to be declared - hence, the procedure can be successfully applied by passive decision-makers, 3) It can be used in the case of totally independent payoff matrices for particular targets. The research takes into account experiment results obtained by [Kahneman 2011] and related to fast and heuristic thinking. The novel rule has been demonstrated by means of an illustrative example concerning the scenariobased bi-criteria single-period newsvendor problem.

In the future it would be desirable to explore the uncertain multi-criteria pure decisionmaking problem on the assumption that payoffs connected with particular decisions are presented as sets (not sequences) of outcomes, since in some real problems, payoffs 
connected with particular investments depend on totally different scenarios (even within the framework of a given criterion).

\section{Bibliography}

Aghdaie M. H., Zolfani S. H., Zavadskas E. K., 2013, Market Segment Evaluation and Selection Based on Application of Fuz:y AHP and COPRAS-G Methods, "Journal of Business Economics and Management" vol. 14(1).

Ben Amor S., Jabeur K., Martel J., 2007, Multiple Criteria Aggregation Procedure for Mixed Evaluations, "European Journal of Operational Research", vol. 181, iss. 3.

Benzion U., Cohen Y., Shavit T., 2010, The Newsvendor Problem with Unknown Distribution, "Journal of the Operational Research Society" iss. 6(6), DOI 10.1057/ jors.2009.56

Besbes O., Muharremoglu A., 2013, On Implications of Censoring Demand in the Newsvendor Problem, "Management Science", vol. 59, iss. 6, DOI 10.2139/ssrn.1983270

Bieniek M., 2016, Bicriteria Optimization in the Newsvendor Problem with Exponentially Distributed Demand, "Multiple Criteria Decision Making", vol. 11.

Caplan B., 2001, Probability, Common Sense, and Realism: A Reply to Hulsmann and Block, "The Quarterly Journal of Austrian Economics", vol. 4, no. 2.

Carnap R., 1950, Logical Foundations of Probability, University Press, Chicago.

De Finetti B., 1975, Theory of Probability. A Critical Introductory Treatment, Wiley, London.

Dominiak C., 2006, Multicriteria Decision aid under Uncertainty, "Multiple Criteria DecisionMaking' 05".

Dominiak C., 2009, Multi-Criteria Decision Aiding Procedure under Risk and Uncertainty, "Multiple Criteria Decision Making' 08'.

Dubois D., Prade H., 2001, Possibility Theory, Probability Theory and Multiple-V alued Logics: A Clarification, "Annals of Mathematics and Artificial Intelligence" vol. 32.

Dubois D., Prade H., 2012, Gradualness, Uncertainty and Bipolarity: Making Sense of Furzy Sets, "Fuzzy Sets and Systems", vol. 192.

Durbach I. N., 2014, Outranking under Uncertainty Using Scenarios, "European Journal of Operational Research", vol. 232, iss. 1.

Durbach I. N., Stewart T. J., 2012, Modeling Uncertainty in Multi-Criteria Decision Analysis, "European Journal of Operational Research", vol. 223, iss. 1.

Eiselt H. A., Marianov V., 2014, Multi-Criteria Decision-Making under Uncertainty: A Visual Approach, "International Transactions in Operational Research", vol. 21, iss. 4.

Fishburn P.C., 1984, Foundations of Risk Measurement. I. Risk or Probable Loss, "Management Science", vol. 30.

Frechet M., 1938, The Diverse Definitions of Probability. »Lecture at the fourth International Congress for the Unity of Science« Erkenntnis.

Gaspars H., 2007, Ressource Allocation under Uncertainty: Choice Models and Computational Procedures [Alokacia zasobu w warunkach niepewności: modele decyzyjne i procedury obliczeniowe]. „,Operations Research and Decisions", vol. 1 (in Polish).

Gaspars-Wieloch H., 2014a, A Hybrid of the Hurvicz and Bayes Rules in Decision-Making under Uncertainty [Propozycja bybrydy regut Hurwicza i Bayesa w podejmowaniu decyzï w warunkach 
niepewności]. T. Trzaskalik (Ed.) „Modelowanie Preferencji a Ryzyko 2014. Studia Ekonomiczne. Zeszyty Naukowe Uniwersytetu Ekonomicznego w Katowicach”, 178, Wydawnictwo Uniwersytetu Ekonomicznego w Katowicach, Katowice (in Polish).

Gaspars-Wieloch H., 2014b, On a Decision Rule for Mixed Strategy Searching under Uncertainty on the Basis of the Coefficient of Optimism, "Procedia - Social and Behavioral Sciences", vol. 110.

Gaspars-Wieloch H., 2014c, Modifications of the Hurvicz's Decision Rules, "Central European Journal of Operations Research", vol. 22, iss. 4.

Gaspars-Wieloch H., 2014d, The Use of a Modification of the Humvicz's Decision Rule in Multicriteria Decision-Making under Complete Uncertainty, "Business, Management and Education", vol. 12, iss. 2.

Gaspars-Wieloch H., 2015a, Modifications of the Omega Ratio for Decision-Making under Uncertainty, "Croatian Operational Research Review”, vol. 6, no. 1.

Gaspars-Wieloch H., 2015b, On a Decision Rule Supported by a Forecasting Stage Based on the Decision-Maker's Coefficient of Optimism, "Central European Journal of Operations Research", vol. 23, iss. 3, DOI 10.1007/s10100-014-0364-5

Gaspars-Wieloch H., 2015c, A Decision Rule for Uncertain Multicriteria Mixed Decision-Making Based on the Coefficient of Optimism, "Multiple Criteria Decision Making '15", University of Economics in Katowice.

Gaspars-Wieloch H., 2015d, On a Decision Rule for Searching an Optimal Pure Strategy in Uncertain Multi-Criteria Decision-Making [O regule decyzyjnej wspierajacej wielokryterialne poszukiwanie optymalnej strategii crystej w warunkach niepewności], "Studia Ekonomiczne. Zeszyty Naukowe Uniwersytetu Ekonomicznego w Katowicach", University of Economics in Katowice (in Polish).

Gaspars-Wieloch H., 2016a, Newsvendor Problem under Complete Uncertainty - A Case of Innovative Products, "Central European Journal of Operations Research", DOI 10.1007/s10100016-0458-3.

Gaspars-Wieloch H., Michalska E., 2016b, On two Applications of the Omega Ratio: MaxSmin and Omega $(H+B)$, "Research Papers of Wrocław University of Economics" (Prace Naukowe Uniwersytetu Ekonomicznego we Wrocławiu), no. 446, Metody i zastosowania badań operacyjnych. Wrocław, 21-36 DOI 10.15611/pn.2016.446.02

Gaspars-Wieloch H., 2017, A Decision Rule Based on Goal Programming and One-Stage Models for Uncertain Multi-Criteria Mixed Decision-Making and Games against Nature, "Croatian Operational Research Review", vol. 8, no. 1.

Ginevičius R., Zubrecovas V., 2009, Selection of the Optimal Real Estate Investment Project Basing on Multiple Criteria Evaluation Using Stochastic Dimensions, "Journal of Business Economics and Management", vol. 10, iss. 3.

Goodwin P., Wright G., 2001, Enhancing Strategy Evaluation in Scenario Planning: A Role for Decision Analysis, "Journal of Management Studies", vol. 38, iss. 1.

Guney S., Newell B.R., 2015, Overcomming Ambiguity Aversion through Experience, "Journal of Behavioral Decision Making", vol. 28, iss. 2.

Guo P., 2011, One-Shot Decision Theory, "IEEE Transactions on Systems, Man, and Cybernetics", Part A, vol. 41, iss. 5. 
Guo P., Ma X. 2014 Newsvendor Models for Innovative Products with One-Shot Decision Theory, "European Journal of Operational Research", vol. 239, DOI 10.1016/j.ejor.2014. 05.028

Hau R., Pleskac T.J., Hertwig R., 2009, Decisions from Experience and Statistical Probabilities: Why they Trigger Different Choices than a priori Probabilities?, "Journal of Behavioral Decision Making", DOI 10.1002/bdm.665

Hopfe C. J., Augenbroe G.L.M., Hensen J.L.M., 2013, Multicriteria Decision-Making under Uncertainty in Building Performance Assessment, "Building and Environment", vol. 69.

Hurwicz L., 1952, A Criterion for Decision-Making under Uncertainty, "Technical Report”, 355, Cowles Commission.

Janjic A., Andjelkovic A., Docic M., 2013, Multiple Criteria Decision-Making under Uncertainty Based on Stochastic Dominance, "Proceedings of the 2013 International Conference on Applied Mathematics and Computational Methods in Engineering" 16-19 July 2013, Rhodes Island, Greece.

Kahneman D., 2011, Thinking, Fast and Slow, Farrar, Straus \& Giroux.

Kaplan S., Barish N.N., 1967, Decision-Making Allowing for Uncertainty of Future Investment Opportunities, "Management Science", vol. 13, iss. 10.

Knight F.H., 1921, Risk, Uncertainty, Profit, Hart. Boston MA, Schaffner \& Marx, Houghton Mifflin Co.

Kolmogorov A. N., 1933, Grundbegriffe der Wahrscheinlichkeitsrechnung, Julius Springer, Berlin.

Korhonen A., 2001, Strategic Financial Management in a Multinational Financial Conglomerate: A Multiple Goal Stochastic Programming Approach, "European Journal of Operational Research", vol. 128.

Lee Y.-H., 2012, A Furay Analytic Network Process Approach to Determining Prospective Competitive Strategy in China: A Case Study for Multinational Biotech Pharmaceutical Enterprises, "Journal of Business Economics and Management", vol. 13, iss. 1.

Liu Y., Fan Z., Hang Y., 2011, A Method for Stochastic Multiple Criteria Decision-Making Based on Dominance Degrees, "Information Sciences", vol. 181, iss. 19.

Liu B., 2007, Uncertainty Theory, 2nd ed., Springer-Verlag, Berlin.

Liu B., 2009, Some Research Problems in Uncertainty Theory, "Journal of Uncertain Systems", vol. 3, no. 1.

Lo M.C., Michnik J., 2010, An Evaluation Method Based on Multi-Attributes Analysis with Stochastic Dominances for Improving the Information Quality, "International Journal of Information Systems for Logistics and Management", vol. 6.

Michnik J., 2013, Scenario Planning+MCD A Procedure for Innovation Selection Problem, "Foundations of Computing and Decision Sciences", 38(3).

Mikhaidov L., Tsvetinov P. 2004 Evaluation of Services Using a Furay Analytic Hierarchy Process, "Applied Soft Computing", vol. 5, iss. 1.

Millett S.M., 2009, Should Probabilities Be Used with Scenarios?, "Journal of Futures Studies", 13(4).

Montibeller G., Gummer H., Tumidei D. 2006 Combining Scenario Planning and Multi-Criteria Decision Analysis in Practice, "Journal of multi-criteria decision analysis" vol. 14.

Ogryczak W., Śliwiński T., 2009, On Efficient WOW A Optimization for Decision Support under Risk, "International Journal of Approximate Reasoning", vol. 50. 
Operations Research [Badania Operacyjne], 2008, W. Sikora (ed), Polskie Wydawnictwo Ekonomiczne, Warsaw (in Polish).

Perez D.E, Hernandez J.G., Garcia M.J., Hernandez G.J., 2015, Hurwicz Method Modified and the Amplitude Model (TAM), In Delener et al. (Ed), GBATA 2015 Reading book, GBATA, USA.

Piasecki K., 2016, Intuicyjne zbiory rozmyte jako narzedzie finansów behawioralnych [Intuitive Fuzzy Sets as a Tool of Behavioral Finances], edu-Libri (in Polish).

Piegat A., 2010, Uncertainty of Probability, Workshop on Intuitionistic Fuzzy Sets and Generalized Nets.

Popper K., 1959, The Propensity Interpretation of Probability, "The British Journal of the Philosophy of Science", 10(37).

Ram C., Montibeller G., Morton A., 2010, Extending the Use of Scenario Planning and MCDA for the Evaluation of Strategic Options, "Journal of Operational Research Society", vol. 62, iss. 5.

Ramík J., Hanclova J., Trzaskalik T., Sitarz S., 2008, Furzy Multiobjective Methods in Multistage Decision Problems, "Multiple Criteria Decision-Making '07”.

Ramsey F., 1931, Truth and Probability, In The Foundations of Mathematics and other Logical Essays, by Frank Ramsey, Routledge, Kegan Paul, London.

Ravindran A. R., 2008, Operations Research and Management Science Handbook, Boca Raton, London, New York, CRS Press.

Shafer G., 1976, A Mathematical Theory of Evidence, Princeton University Press, Princeton. Sentz K., Ferson S., 2002, Combination of Evidence in Dempster-Shafer Theory, Sandia Report SAND2002-0835, April 2002, Albuquerque, NM.

Silva R.C., 2016, A Multiobjective Approach to Solve Container Ship Loading Planning Problem with Uncertainty, Conference Handbook, $28^{\text {th }}$ European Conference on Operational Research, EURO, The Association of European Operational Research Societies.

Stewart T. J., 2005, Dealing with Uncertainties in MCDA, Multiple Criteria Decision Analysis: State-of-the-Art Surveys, "International Series in Operations Research \& Management Science", 78.

Stirling W.C., 2003, Satisficing Games and Decision-Making. With Applications to Engineering and Computer Science, Cambridge University Press.

Suo M.Q., Li Y.P., Huang G.H., 2012, Multicriteria Decision-Making under Uncertainty: An Advanced Ordered Weighted Averaging Operator for Planning Electric Power Systems, "Engineering Applications of Artificial Intelligence", vol. 25, iss. 1.

Troutt M.D., Pettypool M.D., 1989, On the Role of Mixed Strategies in the Elementary Decision Analysis and Related Decision-Support-System Treatments, "Journal of Operational Research Society", vol. 40, iss. 6.

Trzaskalik T., 2008, Introduction to Operations Research with Computer [Wprowadzenie do badan operacyjnych z komputerem], 2nd ed. Polskie Wydawnictwo Ekonomiczne, Warsaw (in Polish).

Trzaskalik T., 2014, Multicriteria Decision Aiding [Wielokryterialne wspomaganie decyzi]], Polskie Wydawnictwo Ekonomiczne, Warsaw (in Polish).

Tsaur S., Chang T., Yen C., 2002, The Evaluation of Airline Service Quality by Furzy MCDM, "Tourism Management", vol. 23, iss. 2. 
Urli B., Nadeau R. 2004 PROMISE/scenarios: An Interactive Method for Multiobjective Stochastic Linear Programming under Partial Uncertainty, "European Journal of Operational Research", vol. 155 , iss. 2.

Van Lambalgen M. 1996 Randomness and Foundations of Probability: von Mises' Axiomatization of Random Sequences. Probability, Statistics and Game Theory, Papers in honor of David Blackwell, Institute for Mathematical Statistics.

Von Mises L., 1949, Human Action: A Treatise on Economics, Yale University Press.

Von Mises R, 1957, Probability, Statistics and Truth, The Macmillan Company, New York.

von Neumann J., Morgenstern O., 1944, Theory of Games and Economic Behavior, Princeton University Press, Princeton, New York.

Wachowicz T., 2015, Methods of Multi-Criteria Decision Analysis in Quantitative Scientific Research [Metody wielokeryterialnej analisy decysyjnej w ilościonych badaniach naukonych], [in:] Podstany metodologii badan w naukach o zarzadzaniu, W. Czakon (ed.), Oficyna Wolters Kluwer business (in Polish)

Walley P., 1991, Statistical Reasoning with Imprecise Probabilities, Chapman and Hall.

Waters D., 2011, Supply Chain Risk. Management. Vulnerability and Resilience in Logistics. Kogan Page.

Weber M., 1987, Decision-Making with Incomplete Information, "European Journal of Operational Research" vol. 28.

Wojewnik P., Szapiro T., 2010, Bireference Procedure FBI for Interactive Multicriteria Optimization with Fuz:y Coefficients, "Central European Journal of Economic Modelling and Econometrics", vol. 2.

Xu R., 2000, Fuz:y Least-Squares Priority Method in the Analytic Hierarchy Process, "Fuzzy Sets and Systems", vol. 112, iss. 3.

Yu C., 2002, A GP-AHP Method for Solving Group Decision-Making Fuгzy AHP Problems, "Computers and Operations Research", vol. 29, iss. 14.

Zadeh L., 1978, Fuгzy Sets as the Basis for a Theory of Possibility, "Fuzzy Sets and Systems" 1.

Zio E., Pedroni N., 2013, Methods for Representing Uncertainty. A Literature Review. Apports de la recherche 2013-3, Risk Analysis. Les cahiers de la securite industrielle, FONCSI. 